\title{
The effect of strain on the thermodynamic properties of Ge-Si, Ge-Sn, Si-Sn, Si-C thin solid films
}

\author{
V. G. Deibuk, Yu.G. Korolyuk \\ Chernivtsi National University, 2 Kotsiubynskogo vul., 58012 Chernivtsi,Ukraine \\ E-mail:vdei@chnu.cv.ua
}

\begin{abstract}
Structural and thermodynamic properties of IV-IV solid solutions were calculated by molecular dynamics simulation. Biaxial strains are extremely important for the miscibility behavior of alloy films. It was shown the existence of critical thickness for the $\mathrm{Ge}_{\mathrm{x}} \mathrm{Si}_{1-\mathrm{x}}$, $\mathrm{Ge}_{1-\mathrm{x}} \mathrm{Sn}_{\mathrm{x}}, \mathrm{Si}_{1-\mathrm{x}} \mathrm{Sn}_{\mathrm{x}}, \mathrm{Si}_{1-\mathrm{x}} \mathrm{C}_{\mathrm{x}}$ thin solid films. The results of the classical molecular dynamic simulations are in good agreement with experimental data and other ab-initio calculations. The effect of layer thickness have great influence on the miscibility gap.
\end{abstract}

Keywords: miscibility, free energy, residual strain, Ge-Si, Ge-Sn, Si-Sn, Si-C thin solid films Paper received 16.07.02; accepted for publication 10.12.02.

\section{Introduction}

Semiconductors with energy gaps in the infrared to farinfrared region are technologically indispensable in photodetectors and emitters opening the possibility of constructing novel, tunable, infrared optoactive devices based on inexpensive and well developed technologies of group-IV semiconductors. The IV-IV semiconductor alloys have recently emerged as a possible candidate for the creation of non-polar semiconductor, with carrier mobilities higher than those of III-V and II-VI compounds. This is of great importance because it can result in new optoelectronic devices based on $\mathrm{Si}$ and $\mathrm{Ge}$, which are indirect gap semiconductors and also the most technologically developed electronic materials. Some of these alloys are $\mathrm{Ge}-\mathrm{Si}, \mathrm{Ge}-\mathrm{Sn}, \mathrm{Si}-\mathrm{Sn}, \mathrm{Si}-\mathrm{C}, \mathrm{SiGeSn}, \mathrm{SiGeC}$. Most of these materials are new, nevertheless, not all of these compositions are thermodynamically stable. In fact, many compositions do not form solid solutions. Using the equilibrium growth techniques it is often possible to confine segregation and causes precipitation with one or more elements. However, this difficulty can be overcome by nonequilibrium growth or metastable growth techniques such as molecular-beam epitaxy and laser crystallization. Most of these alloys have miscibility gaps. But Stringfellow showed that the materials with stress and strain would have narrower or no miscibility gaps [1]. The stress and strain in the materials grown by epitaxy methods such as molecular beam epitaxy (MBE), metal organic chemical vapor deposition (MOCVD) are mainly caused by the lattice mismatch between epilayer and substrate. The effect of strain relaxation also has influence on the phase transition and stability of solids.
In this paper, the influence of residual strains on the miscibility gaps of Si-Ge, Ge-Sn, Si-Sn, Si-C was calculated by molecular dynamics method and the ranges of miscibility gaps have been determined.

Using $\mathrm{Ge}_{\mathrm{x}} \mathrm{Si}_{1-\mathrm{x}}$ alloys, it has recently become possible to create electronic devices that outperform traditional silicon technology, yet remain compatible with standard manufacturing method [2]. On the other hand, theoretical investigations [3] suggest that substitutional C plays a different role in Si than substitutional Ge and tends to decrease the band gaps rather than enlarge them (as would be expected from a simple virtual-crystal picture).

Soma et al. [4] studied the effect of stress on phase diagrams of Ge-Sn and Si-Sn alloys. They predicted the enlargement of stability region of Ge-Sn solid solutions under an external pressure. A common feature of the alloy epitaxies is the strain due to lattice mismatch and different thermal expansion coefficients. The epitaxial layer of binary alloy grown pseudomorphically on the substrate becomes highly strained. The strain and compositional fluctuations influence all types of properties of the alloys including the miscibility.

The covalent system of Ge-Si solid solutions forms continuous substitutional solid solutions and does not change the number of bonding electrons when the solid solutions are formed. Recently interest in $\mathrm{Ge}_{x} \mathrm{Si}_{1-\mathrm{x}}$ alloys and superlattices [5] has been renewed. Lattice constants of silicon and germanium differ by $\sim 4 \%$. Hence, strains introduced during formation of $\mathrm{Ge}_{x} \mathrm{Si}_{1-x}$ alloys can affect the band structure and transport properties [6]. Furthermore, by growing Ge-Si layers on substrates of different lattice constants, or by modifying the thickness ratio of the layers in a free-standing superlattice, one can 


\section{G. Deibuk et al.: The effect of strain on the thermodynamic properties of...}

control the strains in the layers, and modify significantly the electronic properties [7]. $\mathrm{Ge}_{\mathrm{x}} \mathrm{Si}_{1-\mathrm{x}}$ is indirect-gap semiconductor. The difference between lattice constants of alloy and "native" substrates results in inherent strains of the alloy grown on a substrate, which yields in a significant modification of $\mathrm{Ge}_{\mathrm{x}} \mathrm{Si}_{1-\mathrm{x}}$ alloy band structure.

$\mathrm{Ge}_{1-\mathrm{x}} \mathrm{Sn}_{\mathrm{x}}$ is predicted to exhibit a direct band gap in unstrained alloys, tunable from $\approx 0.55 \mathrm{eV}$ to $0 \mathrm{eV}$ with $x$ ranging from 0.20 to 0.65 as the $\Gamma$-point conduction band minimum decreases more rapidly than the $L$ point valleys [8]. Moreover, the presence of compressive strain is expected to decrease the $\mathrm{Sn}$ concentration at which the indirect $L_{6}{ }^{+} \rightarrow \Gamma_{8}{ }^{+}$to direct $\Gamma_{7}^{-} \rightarrow \Gamma_{8}{ }^{+}$band gap crossover is observed. Soref and Friedman [9] have used virtual-crystal linear extrapolations of $\Gamma$ and $L$ point energies as a function of strain to estimate a reduction at room-temperature of cross-over from $x \approx 0.2$ in relaxed $\mathrm{Ge}_{1-\mathrm{x}} \mathrm{Sn}_{\mathrm{x}}$ to $x \approx 0.02$ in $\mathrm{Ge}_{1-\mathrm{x}} \mathrm{Sn}_{\mathrm{x}} / \mathrm{Ge}(001)$ compressively strained heterostructures. In addition to its potential technological importance, $\mathrm{Ge}_{1-\mathrm{x}} \mathrm{Sn}_{\mathrm{x}}$ also serves as a model system for investigating epitaxial growth in thermodynamically metastable alloys. The diamond-structure $\alpha$ $\mathrm{Sn}$ is stable only at temperatures below $13.2^{\circ} \mathrm{C}$ and equilibrium solid solubilities in the $\mathrm{Ge}_{1-\mathrm{x}} \mathrm{Sn}_{\mathrm{x}}$ system are extremely low, less than 1 at. $\%$ on both sublattices. Furthermore, Sn atoms are easily solvable in Ge lattice with a strong tendency to surface segregation. But recently, epitaxial metastable $\mathrm{Ge}_{1-\mathrm{x}} \mathrm{Sn}_{\mathrm{x}}$ alloys with $x$ up to 0.26 were grown on $\mathrm{Ge}(001) 2 \times 1$ by low-temperature molecular beam epitaxy [10].

$\mathrm{Si}_{1-\mathrm{x}} \mathrm{Sn}_{\mathrm{x}}$ alloy would ideally have a band gap between those of silicon and tin. $1.153 \mathrm{eV}$ and $0.08 \mathrm{eV}$, which is very important for IR detector applications. Also, the band gap was predicted by R. Soref [11] to be direct for the compositional range of $0.9<x<1$ and indirect for another one. Strained layers of $\mathrm{Si}_{1-x} \mathrm{Sn}_{\mathrm{x}}$ alloy semiconductors would find numerous applications in electronic and optoelectronic heterostructures. The pseudomorphic $\mathrm{Si}_{0.96} \mathrm{Sn}_{0.04}$ was grown by A.Khan [12] using the molecular beam epitaxy with the epilayer thickness close to $150 \mathrm{~nm}$.

Diamond with its very wide band gap of $5.5 \mathrm{eV}$ is a possible candidate for making a wide band-gap Si-based material that can be integrated with Si. However, diamond has a much smaller lattice parameter than $\mathrm{Si}$, which makes the structural aspects of Si-C alloy system quite unlike those of $\mathrm{Ge}_{\mathrm{x}} \mathrm{Si}_{1-\mathrm{x}}$ alloys. The main obstacle to the realization of this program is extremely low solubility of $\mathrm{C}$ in $\mathrm{Si}$. Even at the melting point of $\mathrm{Si}$, it is only about $10^{-6}$ at. $\%$. This problem has been partially overcome recently. The first successful attempt to grow $\mathrm{Si}_{1-\mathrm{x}} \mathrm{C}_{\mathrm{x}}$ alloys was reported by Posthill et al. [13]. Using remote plasma-enhanced chemical-vapor deposition this group fabricated a $7-\mu \mathrm{m}$-thick layer with a carbon concentration of about $3.5 \%$. Furthermore, Iyer et al. [14] used solid source molecular-beam epitaxy to grow pseudomorphic $\mathrm{Si}_{1-\mathrm{x}} \mathrm{C}_{\mathrm{x}}$ layers with $x>0.002$ and strained layered superlattices stable up to $800^{0} \mathrm{C}$ (for $x=0.003$ ). Their material also contained about $1 \%$ Ge to compensate for strain effects.

\section{Computational method}

The purpose of this work is to predict the thermodynamic properties of $\mathrm{Ge}_{\mathrm{x}} \mathrm{Si}_{1-\mathrm{x}}, \mathrm{Ge}_{1-\mathrm{x}} \mathrm{Sn}_{\mathrm{x}}, \mathrm{Si}_{1-\mathrm{x}} \mathrm{Sn}_{\mathrm{x}}, \mathrm{Si}_{1-\mathrm{x}} \mathrm{C}_{\mathrm{x}}$ solid solutions in bulk and epilayer cases by molecular dynamics simulation. We used the Tersoff three-particle potential, which is the most successful for studying the structural, dynamical, and thermodynamical properties of many crystals and alloys. Interatomic Tersoff's potential for interaction energy of two neighbor atoms $i$ and $j$ has the form[15]:

$V_{i j}=f_{C}\left(r_{i j}\right)\left[a_{i j} f_{R}\left(r_{i j}\right)+b_{i j} f_{A}\left(r_{i j}\right)\right]$,

where

$$
\begin{aligned}
& f_{R}(r)=A \cdot \exp (-\lambda r) \\
& f_{A}(r)=-B \cdot \exp (-\mu r)
\end{aligned}
$$

$$
f_{C}(r)=\left\{\begin{array}{lr}
1, & r<R \\
\frac{1}{2}+\frac{1}{2} \cos \left[\frac{\pi}{2} \frac{(r-R)}{(S-R)}\right], & R<r<S \\
0, & r>S
\end{array}\right.
$$

Parameters for Ge, Si and C were taken from [15], and for $\mathrm{Sn}$ were derived from gray-tin cohesion energy adjustment, equal to $3.12 \mathrm{eV}$ per atom [16]. Simulations have been done for systems with $N=216$ particles, the initial positions of which were taken in tetrahedral sites of cell, formed by $3 \times 3 \times 3$ unit cells of the diamond type. The periodic boundary conditions were used. This method was based on solving the Newton equation set using the fast form of Verlet algorithm [17], which being self-starting, doesn't lead to roundoff errors accumulation. Simulation is started from an initial structure, in which two kinds of atoms are randomly placed on the diamond lattice.

In order to study stability properties of $\mathrm{Ge}_{\mathrm{x}} \mathrm{Si}_{1-\mathrm{x}}$, $\mathrm{Ge}_{1-\mathrm{x}} \mathrm{Sn}_{\mathrm{x}}, \mathrm{Si}_{1-\mathrm{x}} \mathrm{Sn}_{\mathrm{x}}$ and $\mathrm{Si}_{1-\mathrm{x}} \mathrm{C}_{\mathrm{x}}$ alloys, we calculated the Helmholz mixing free energies as functions of $x$. For a disordered binary alloys the Helmholz mixing free energy $\Delta F$ is a function of $x$ and $T$ at a fixed pressure:

$\Delta F(x, T)=F_{A B}(x, T)-(1-x) F_{A}(T)-x F_{B}(T)$

Then $\Delta F$ can be written as

$\Delta F=\Delta E-T \Delta S$

where $\Delta E$ is the mixing energy and $\Delta S$ is the mixing entropy defined similarly to $\Delta F$. Because the magnitude of $\Delta(P V)$ is small at the normal pressure of about 1 atmosphere, $\Delta E$ and mixing enthalpy $\Delta H$ are interchangeable. The entropy of mixing is supposed to be equal to the configurational entropy in the regular-solution model, given by

$\Delta S=-R[(1-x) \ln (1-x)+x \ln x]$

When the free energy versus composition curve contains an inflection point, the solid solutions will decom- 


\section{G. Deibuk et al.: The effect of strain on the thermodynamic properties of...}

pose, which is called spinodal decompositions. The products of the decompositions are two solid solutions with different compositions. The stability criterion for binary or peseudobinary alloys is $\partial^{2} G / \partial x^{2}>0$. The unstable region is defined by the locus of $\partial^{2} G / \partial x^{2}=0$. Then the miscibility gap can be determined. In the same way we determined the metastable boundaries, the so-called binodals. Thus, the binodal of semiconductor alloys is defined by the locus of $\partial G / \partial x=0$.

If the epilayer and substrate are lattice-mismatched, strain will be produced in the epilayer. The total Helmholz free energy of the system is the sum of the Helmholz free chemical energy of the bulk alloys and the strain energy: $F_{\text {EPICASE }}=F_{B U L K}+E_{\text {STRAIN }}$

$E_{S T R A I N}$ is the strain energy of epitaxialy strained semiconductor alloys per unit volume, and can be written as[18]:

$$
E_{\text {STRAIN }}=\frac{E \varepsilon^{2}}{1-v},
$$

where $E$ is Young's modulus of elasticity, $v$ - Poisson's ratio.

In real epilayers, only when the thickness of the epilayer is less than the critical thickness, the epilayer is fully strained, otherwise it will relax by generating mismatch dislocations. The thicker the epilayer, the smaller the residual strain. Under such conditions, the strain effect will decrease. To find the influence of relaxation on the solid phase transition, residual strain has to be quantitatively determined.

From the balance condition of force acting on threading dislocations, the residual strain is inversely proportional to the thickness of the epilayer[19]:

$\varepsilon=\frac{A_{0}}{h}$

where $h$ is the thickness of the epilayer and $A_{0}$ is a constant. For the force balance model, the critical thickness $h_{C}$ of epilayer can be described as:

$$
h_{C}=\left(\frac{b}{f}\right)\left[\frac{1}{4 \pi(1+v)}\right] \cdot\left[\ln \left(\frac{h_{C}}{b}+1\right)\right]
$$

where $b$ is the Burgers vector and $f$ - the lattice mismatch between the epilayer and substrate. In our semiconductor epilayers, the most common mismatch dislocations are $60^{\circ}$ dislocations, Burgers vectors of which are $(a / 2)<110>$, and $b=a / \sqrt{2}$. To figure out $A_{0}$, we can assume that when $h=h_{C}, \varepsilon=f$. So $A_{0}=f \cdot h_{C}$. The range of the miscibility gap can be calculated from equations (3)-(11) and the stability criterion.

\section{Results and discussions}

\section{A. $G e_{x} S i_{1-x}$ thin solid films}

The model described above can be used to determine the miscibility gap of Ge-Si, Ge-Sn, Si-Sn, Si-C binary solid

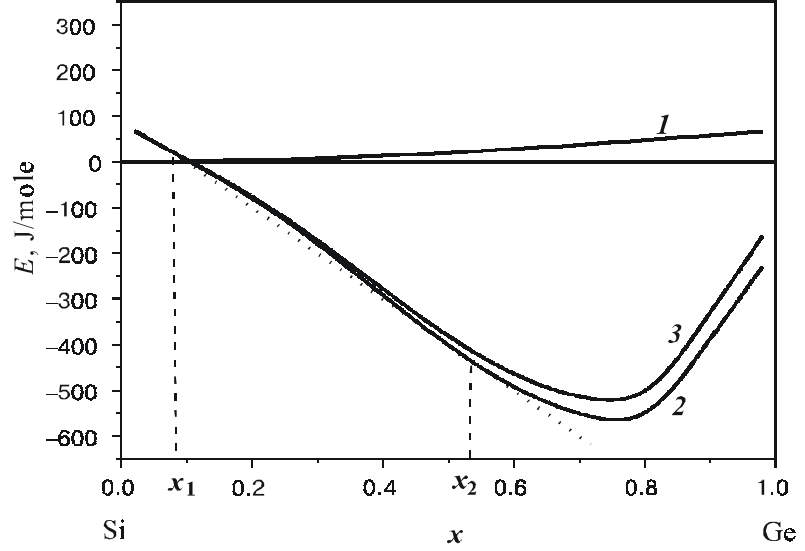

Fig. 1. Enthalpy of formation and strain energy for $\mathrm{Ge}_{\mathrm{x}} \mathrm{Si}_{1-\mathrm{x}}(T=$ $=180 \mathrm{~K}) .1-E_{\text {STRAIN }}\left(\mathrm{GeSi} / \mathrm{Si}, h<h_{C}\right) ; 2-\mathrm{DH}$ (bulk GeSi); $3-$ DH $\left(\mathrm{GeSi} / \mathrm{Si}, h<h_{C}\right)$.

solutions grown on "native" substrate. The parameters used in the calculation are listed in Table 1.

If the epilayer $\mathrm{Ge}_{\mathrm{x}} \mathrm{Si}_{1-\mathrm{x}}$ is fully strained (no relaxation takes place), the strain energy increases with the increasing of $x$. In Fig.1, lines 1 and 2 show the composition dependence of strain and chemical energy in $\mathrm{Ge}_{\mathrm{x}} \mathrm{Si}_{1-\mathrm{x}}$ epilayer grown on Si substrate, respectively. The layer thickness is less than critical and the temperature of the solutions is $180 \mathrm{~K}$. Line 2 has two minima that have common tangents (dotted line) and indicates that spinodal decomposition will take place if the strain energy is not included (bulk Ge-Si). Line 3 is the sum of two kinds of energy. Then the two minima existing in line 1 disappear, and $\partial^{2} G / \partial x^{2}<0$. It means that spinodal decompositions will not occur and strain energy stabilizes the epilayer. The fundamental method of determining the composition of decomposition products is drawing of a common tangent to the composition-dependent Helmholz free energy (dotted line in Fig. 1). The two tangent points $x_{1}$ and $x_{2}$ represent the compositions of equilibrium phases after the decomposition (in this case $T=180 \mathrm{~K}$ ). The results of analyses of the Helmholz free energy for bulk and epistrained Ge-Si are presented in Fig.2. Line 1 represents the miscibility gap for bulk $\mathrm{Ge}_{\mathrm{x}} \mathrm{Si}_{1-\mathrm{x}}$ alloys. Points $x_{1}$ and $x_{2}$ determined in Fig. 1 meet the $x$ points on binodal line 1 in Fig. 2 at $T=180 \mathrm{~K}$. Lines 2 and 3 represent the miscibility gaps for epistrained $\mathrm{Ge}_{\mathrm{x}} \mathrm{Si}_{1-\mathrm{x}}$ alloys with thickness of epilayer equal $150 \AA$ and $h<h_{C}$ (only effects of strain), respectively. When the layer thickness decreases, the strain effect increases, and the miscibility gap narrows. When the strain effect is taken into account, we observe that the left tangent's point on the Helmholz free

Table 1. Parameters used in the calculations [20]

\begin{tabular}{llll}
\hline \hline & $\begin{array}{c}\text { Lattice } \\
\text { parameter }(\AA)\end{array}$ & $\begin{array}{c}\text { Young's modulus } \\
\text { of elasticity } \\
\left(\mathrm{N} / \mathrm{m}^{2}\right)\end{array}$ & Poisson ratio \\
\hline $\mathrm{C}$ & 3.567 & $6.9 \times 10^{12}$ & 0.25 \\
\hline $\mathrm{Si}$ & 5.43 & $1.1 \times 10^{11}$ & 0.266 \\
\hline $\mathrm{Ge}$ & 5.658 & $7.58 \times 10^{10}$ & 0.28 \\
\hline$\alpha-\mathrm{Sn}$ & 6.49 & $4.69 \times 10^{10}$ & 0.36 \\
\hline \hline
\end{tabular}




\section{G. Deibuk et al.: The effect of strain on the thermodynamic properties of...}

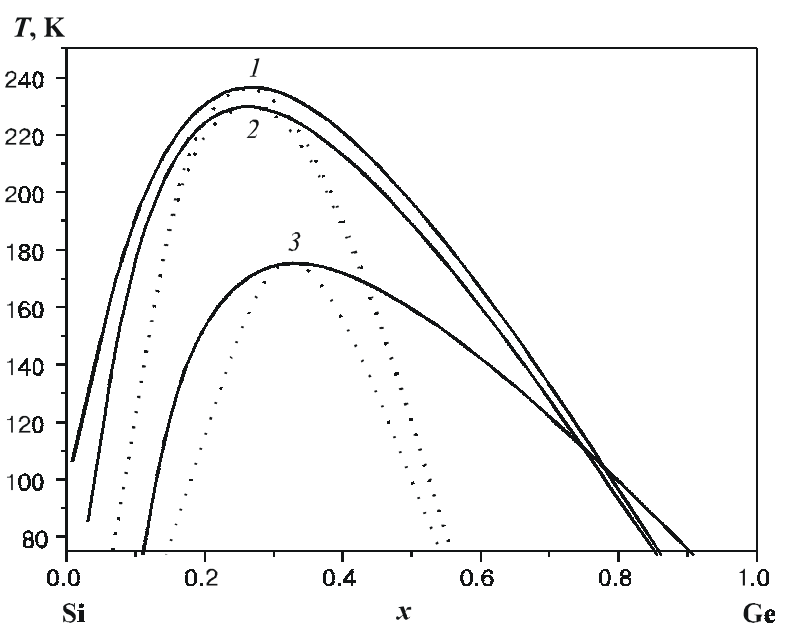

Fig. 2. Spinodal and binodal decomposition range for bulk and epistrained $\mathrm{Ge}_{\mathrm{x}} \mathrm{Si}_{1-\mathrm{x}} / \mathrm{Si}$ alloy with various thickness of epilayer. 1 - bulk $\mathrm{Ge}_{\mathrm{x}} \mathrm{Si}_{1-\mathrm{x}} ; 2-\mathrm{Ge}_{\mathrm{x}} \mathrm{Si}_{1-\mathrm{x}} / \mathrm{Si}(001) h=50 \AA$ 皮 $3-\mathrm{Ge}_{\mathrm{x}} \mathrm{Si}_{1-\mathrm{x}} / \mathrm{Si}$ (001) $h<h_{C}$. Solid lines - binodals, dotted lines - spinodals.

energy shifts to the right (high Ge content terminal) and the position of the right tangent point changes only slightly. It suggests that the miscibility gap becomes smaller. Fig. 2 shows that the critical temperature decreases with strain energy and relaxation. The reason is that the epilayer with high Ge composition has a large mismatch with a Si substrate, so the critical thickness is very small, even thinner than a single atom layer line 1 in Fig.3. As a result, the epilayer with any thickness is totally relaxed, and the residual strain is very small. Hence, the effect of strain is very small. On the contrary, if the Si composition is high, the residual strain is sensitive to the layer thickness.

We have a good agreement of our critical thickness calculations for $\mathrm{Ge}_{\mathrm{X}} \mathrm{Si}_{1-\mathrm{x}} / \mathrm{Si}$ with experimental work of Bolhovitanov et al. [21] (Fig. 3) Furthermore, the critical temperature $T_{C}=235 \mathrm{~K}$ for bulk $\mathrm{Ge}_{\mathrm{x}} \mathrm{Si}_{1-\mathrm{x}}$ is in a good agreement with other ab-initio methods of calculations that include electronic interactions: $T_{C}=240 \mathrm{~K}$ [4].

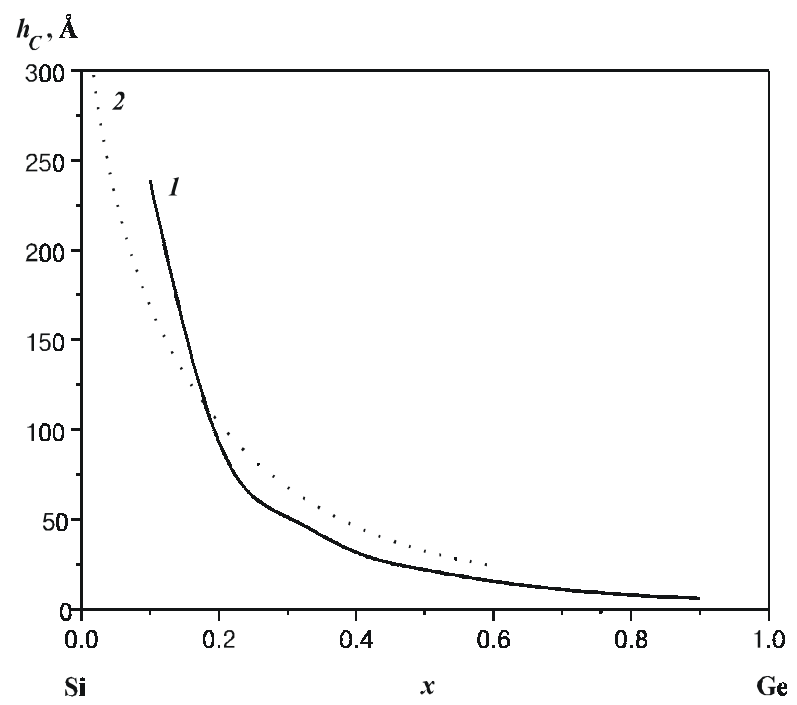

Fig. 3. Critical thickness for $\mathrm{Ge}_{\mathrm{X}} \mathrm{Si}_{1-\mathrm{x}} / \mathrm{Si}$ alloy. $1-\mathrm{Ge}_{\mathrm{X}} \mathrm{Si}_{1-\mathrm{x}} / \mathrm{Si}(001)-$ our calculations; $2-\mathrm{Ge}_{\mathrm{x}} \mathrm{Si}_{1-\mathrm{x}} / \mathrm{Si}(001)$ [22].

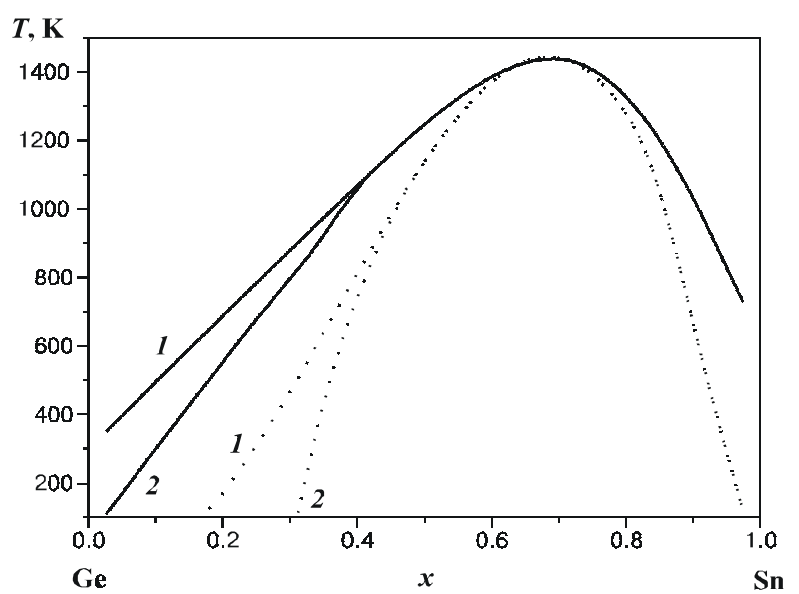

Fig. 4. Spinodal and binodal decomposition range for the $\mathrm{Ge}_{1-\mathrm{x}} \mathrm{Sn}_{\mathrm{x}}$ alloy in bulk and epitaxial cases. 1 - bulk GeSn; $2-\mathrm{GeSn} / \mathrm{Ge}(001) h=25 \AA$ A. Solid lines - binodals, dotted lines spinodals.

\section{B. Ge $e_{1-x} S n_{x}$ thin solid films}

Our next step was to calculate diagrams of stability for disordered $\mathrm{Ge}_{1-\mathrm{x}} \mathrm{Sn}_{\mathrm{x}}$ solutions (Fig. 4). We showed that this alloy has a metastable region at $0<x<0.18$ at $T=100 \mathrm{~K}$. Modelling a film-type GeSn pseudomorphic alloy ( $h=25 \AA$ ) on Ge substrate showed the increasing of metastable region to $x \approx 0.3$ at $T=100 \mathrm{~K}$. But we did not observe the common decreasing of critical temperature. This fact can be partially explained with finiteness of critical thickness GeSn/Ge. The relaxation energy by means of mismatch dislocations compensates the strain energy, if thickness of layer was larger than critical. Analizing the experimental techniques of this alloy growing [10], we came to conclusion that practical preparation of $\mathrm{GeSn} / \mathrm{Ge}$ alloy at $0<x<0.20$ can be done only by low-temperature growth techiques. These techniques confines the decomposition processes that are caused by the temperature and diffuse tendency in alloy for the step of formation. In Fig. 5 shown are our calculations of

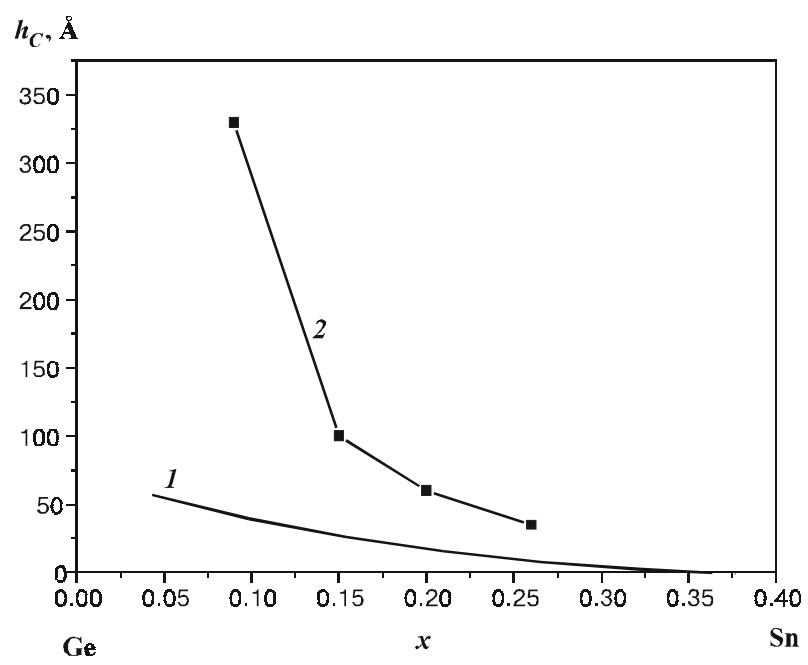

Fig. 5. Critical thickness for $\mathrm{Ge}_{1-\mathrm{x}} \mathrm{Sn}_{\mathrm{x}} / \mathrm{Ge}$ alloy. $1-\mathrm{Ge}_{1-\mathrm{x}} \mathrm{Sn}_{\mathrm{x}} / \mathrm{Ge}$ (001) - our calculations; $2-\mathrm{Ge}_{1-\mathrm{x}} \mathrm{Sn}_{\mathrm{x}} / \mathrm{Ge}(001)$ [10]. 


\section{G. Deibuk et al.: The effect of strain on the thermodynamic properties of...}

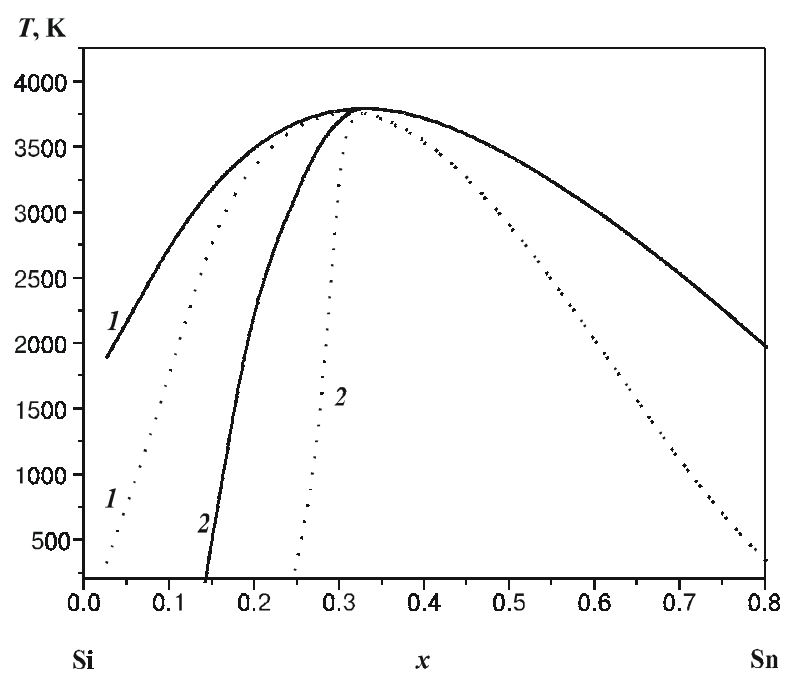

Fig. 6. Spinodal and binodal decomposition range for the $\mathrm{Si}_{1-\mathrm{x}} \mathrm{Sn}_{\mathrm{x}}$ alloy in bulk and epitaxial case. $1-$ bulk $\mathrm{SiSn} ; 2-\mathrm{SiSn} /$ $\mathrm{Si}(001) h=25 \AA$. Solid lines - binodals, dotted lines - spinodals.

critical thickness for disordered $\mathrm{Ge}_{1-\mathrm{x}} \mathrm{Sn}_{\mathrm{x}}$ solid solutions on $\mathrm{Ge}(001)$ substrate. The critical thickness exists only for $0<x<0.35$, because the lattice mismatch between $\mathrm{Ge}$ and $\mathrm{Sn}$ is $13.9 \%$. Moreover we show in Fig. 5 the experimental data of $\mathrm{h}_{\mathrm{C}}$ for $\mathrm{GeSn} / \mathrm{Ge}[10]$. We have some variance between experimental and calculated data that can be explained by different interpretations of the "critical thickness" term. The authors in [10] understand the critical thickness as the thickness when the alloy becomes amorphous. We understand $\mathrm{h}_{\mathrm{C}}$ as a boundary thickness of film when the mismatch dislocations appear, that is the classical formulation of the "critical thickness" concept.

\section{C. $S i_{1-x} S n_{x}$ thin solid films}

We show the stability diagram for disordered $\mathrm{Si}_{1-\mathrm{x}} \mathrm{Sn}_{\mathrm{x}}$ solutions in Fig. 6. $\mathrm{Si}_{1-\mathrm{x}} \mathrm{Sn}_{\mathrm{x}}$ alloy is less stable than $\mathrm{Ge}_{1-\mathrm{x}} \mathrm{Sn}_{\mathrm{x}}$, because there is a bigger lattice mismatch be-

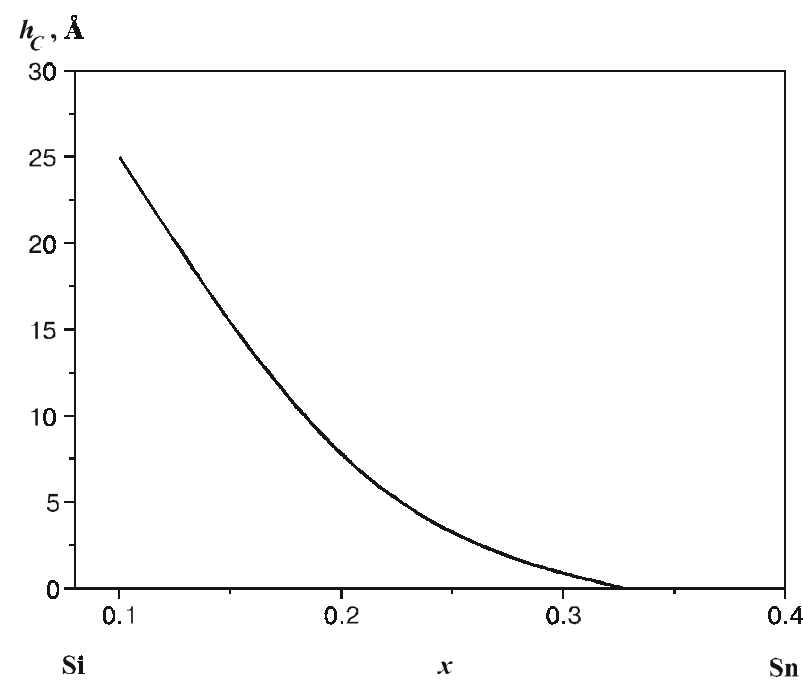

Fig. 7. Critical thickness for $\mathrm{Si}_{1-\mathrm{X}} \mathrm{Sn}_{\mathrm{x}} / \mathrm{Si}$ alloy. tween $\mathrm{Si}$ and $\mathrm{Sn}(17.9 \%)$ than between Ge and $\mathrm{Sn}(13.9 \%)$ components. Larger instability of SiSn solutions can be observed by increasing the critical temperature of spinodal decompositions in contrast to the alloys presented before. The diagrams of stability for strained $\mathrm{Si}_{1-\mathrm{x}} \mathrm{Sn}_{\mathrm{x}}$ film on Si substrate with $h=25 \AA$ Are shown in Fig. 6. One can see that substrate has a great influence on spinodal region of $\mathrm{SiSn}$, for example metastable region increase to $x \approx 0.247$, and stable one - to $x \approx 0.146$ at $T=200 \mathrm{~K}$. We did not observe the total decreasing of critical temperature, similarly to $\mathrm{Ge}_{1-\mathrm{x}} \mathrm{Sn}_{\mathrm{x}} / \mathrm{Ge}$. Furthermore, the behavior of critical thickness of $\mathrm{GeSn} / \mathrm{Si}$ films $h_{C}=f(x)$ (Fig.7) is similar to the alloys presented before and is equal to 0 at $x>0.32$.

\section{D. $S i_{1-x} C_{x}$ thin solid films}

The formation enthalpy of disordered (D) and ordered (O) (zinc-blende phase - ZB) $\mathrm{Si}_{0.5} \mathrm{C}_{0.5}$ (Fig. 8) was evaluated for accurate modelling and for explanation of special behavior of $\mathrm{Si}_{1-\mathrm{x}} \mathrm{C}_{\mathrm{x}}$ phase diagrams. Our calculations showed that formation enthalpy for disordered case is $\Delta H_{\mathrm{D}-\mathrm{SiC}}=1.81 \mathrm{eV} /$ atom, and for ordered $\Delta H_{\mathrm{O}-\mathrm{SiC}}=$ $=-0.385 \mathrm{eV} /$ atom. Hence, ordered ZB-phase is more stable and more advantageous than disordered phase of $\mathrm{SiC}$ alloy. One can see great ordering tendency at $x=0.5$ in $\mathrm{Si}_{1-\mathrm{x}} \mathrm{C}_{\mathrm{x}}$ that explains existing of chemical ordered $\mathrm{Si}-\mathrm{C}$ compound on phase diagrams. Fig. 8 shows the data of other theoretical enthalpy calculations [22] in generalized functional approximation to the density functional theory for ordered SiC. We have a good agreement for the formation enthalpy between our classical moleculardynamics calculations and other calculations including electron interactions: $\left(\Delta H_{\mathrm{O}-\mathrm{SiC}}=-0.385 \mathrm{eV} / \mathrm{atom}\right.$ (our calculations), $\Delta H_{\mathrm{O}-\mathrm{SiC}}=-0.378 \mathrm{eV} /$ atom [22]). The minimum of formation enthalpy for ZB-SiC (Fig. 8) corresponds to the equilibrium volume $\left(V=76.22 \AA^{3}=>\right.$ $a=4.24 \AA$ ) analogously determined for all sequences of $x$ data.

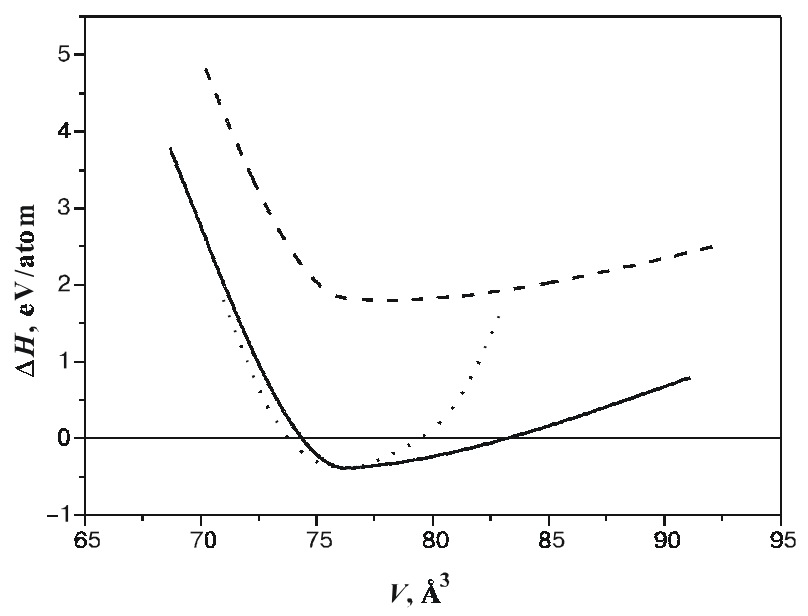

Fig. 8. Enthalpy of formation for $\mathrm{Si}_{0.5} \mathrm{C}_{0.5}$ disordered and ZBordered alloys. Solid line - ZB SiC; dashed line - disorder SiC; dotted line - ZB SiC[22]. 


\section{G. Deibuk et al.: The effect of strain on the thermodynamic properties of...}

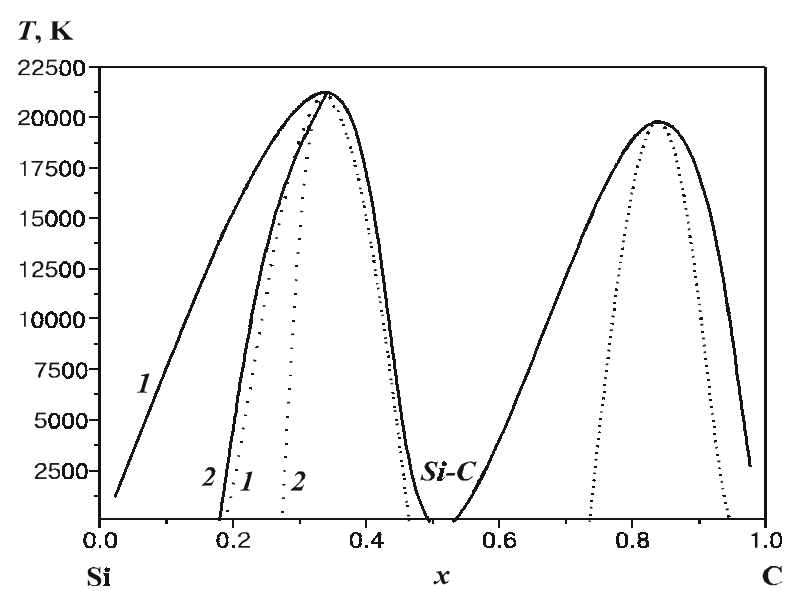

Fig. 9. Spinodal and binodal decomposition range for the $\mathrm{Si}_{1-\mathrm{x}} \mathrm{C}_{\mathrm{x}}$ alloy in bulk and epitaxial case. $I-$ bulk $\mathrm{Si}_{1-\mathrm{x}} \mathrm{C}_{\mathrm{x}} ; 2-\mathrm{Si}_{1-\mathrm{x}} \mathrm{C}_{\mathrm{x}} / \mathrm{Si}$ ( $h=10 \AA$ ). Solid lines - binodals, dotted lines - spinodals.

We constructed the diagram of stability for $\mathrm{Si}_{1-\mathrm{x}} \mathrm{C}_{\mathrm{x}}$ ordered solutions in bulk and epitaxial case (Fig. 9) by the methods described before. The solubility of $\mathrm{C}$ in $\mathrm{Si}$ is very small and even at Si melting-point it is only $10^{-6} \%$. Moreover, big lattice mismatches make the growing process of bulk $\mathrm{Si}_{1-\mathrm{x}} \mathrm{C}_{\mathrm{x}}$ impossible at normal conditions that we can see in Fig. 9. The behavior of spinodal and binodal boundaries defines three regions in which alloy is in stable or metastable phase at $T=100 \mathrm{~K}(1-0<x<0.18 ; 2-$ $0.46<x<0.74 ; 3-0.95<x<1)$. We found the existence of critical thickness for epistrained $\mathrm{Si}_{1-x} \mathrm{C}_{\mathrm{x}}$ on $\mathrm{Si}$ substrate in the first region. Experimental works [13] showed that only in this region pseudomorphic $\mathrm{Si}_{1-\mathrm{x}} \mathrm{C}_{\mathrm{x}} / \mathrm{Si}$ alloys at $x=3.5 \%$ can be grown. We modelled thin layer of $\mathrm{Si}_{1-\mathrm{x}} \mathrm{C}_{\mathrm{x}}$ with $h=10 \AA$. The influence of substrate deformation on stability is considerable, as shown in Fig. 9. The stable region was increased to $x \approx 0.18$, and metastable to $x \approx 0.27$ at $T=100 \mathrm{~K}$. These data make possible to grow biaxially strained $\mathrm{Si}_{1-\mathrm{x}} \mathrm{C}_{\mathrm{x}}$ films at $x<0.2$. The behavior of critical thickness of $\mathrm{Si}_{1-\mathrm{x}} \mathrm{C}_{\mathrm{x}} / \mathrm{Si}$

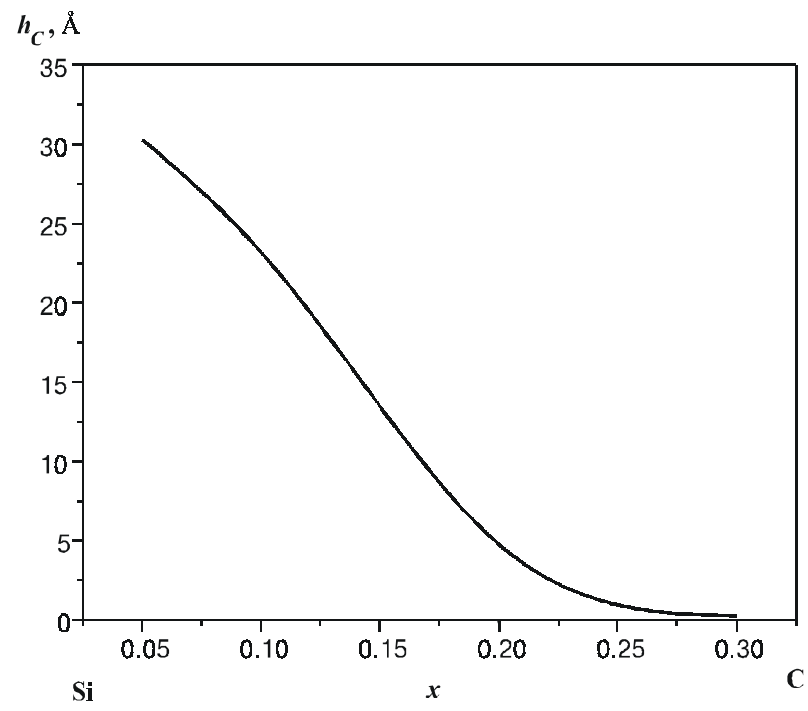

(001) alloy (Fig.10) is similar to $\mathrm{A}^{\mathrm{IV}}-\mathrm{B}^{\mathrm{IV}}$ alloys investigated before. Small values of $\mathrm{h}_{\mathrm{C}}$ to similar $x$ values in other solid solutions can be explained by the largest lattice mismatch of components in $\mathrm{Si}_{1-\mathrm{x}} \mathrm{C}_{\mathrm{x}}(41.6 \%)$ and so the most limited influence of strain energy on stability of epitaxially grown alloy.

\section{Summary}

An molecular dynamics approach to calculate the miscibility gap of $\mathrm{Ge}_{\mathrm{x}} \mathrm{Si}_{1-\mathrm{x}}, \mathrm{Ge}_{1-\mathrm{x}} \mathrm{Sn}_{\mathrm{x}}, \mathrm{Si}_{1-\mathrm{x}} \mathrm{Sn}_{\mathrm{x}}$, and $\mathrm{Si}_{1-\mathrm{x}} \mathrm{C}_{\mathrm{x}}$ binary systems has been proposed. The approach includes both the strain energy and the relaxation effect. The strain effect results in diminishing the miscibility gap. The thinner the epilayer, the smaller the miscibility gap. The critical layer thickness also decreases with compositions $x$. We have a good agreement with experimental data for critical thickness of $\mathrm{GeSi} / \mathrm{Si}$ and $\mathrm{GeSn} / \mathrm{Ge}$. Formation enthalpies for disordered and ordered $\mathrm{Si}_{0.5} \mathrm{C}_{0.5}$ alloys were calculated and the stability as well as validity of our ZB$\mathrm{SiC}$ model were grounded, too. The diagrams of stability for $\mathrm{Ge}_{\mathrm{x}} \mathrm{Si}_{1-\mathrm{x}}, \mathrm{Ge}_{1-\mathrm{x}} \mathrm{Sn}_{\mathrm{x}}, \mathrm{Si}_{1-\mathrm{x}} \mathrm{Sn}_{\mathrm{x}}, \mathrm{Si}_{1-\mathrm{x}} \mathrm{C}_{\mathrm{x}}$ binary solid solutions were built, and the influence of different thickness of "native" layers on stability of these alloys with epitaxial deformations was calculated. The effect of layer thickness will have great influence on the miscibility gap.

\section{References}

1. G.B.Stringfellow, Spinodal decomposition and clustering in III/V alloys. // J. Electron. Mater. 11(5), pp.903-918 (1982).

2. J.D.Cressler, SiGe HBT technology: A new contender for Si-based RF and microwave circuit applications // IEEE Trans. Micro. Theory Techniques 46(5), pp.572-589 (1998).

3. A.Demkov, O.Sankey, Theoretical investigation of random Si-C alloys // Phys. Rev. B. 48(4), pp. 2207-2214 (1992).

4. T.Soma, K.Kamada, H.Kagaya, The pressure effect on the Phase Diagrams of the Ge-Sn and Si-Sn Systems // Phys. Stat. Sol.(b) 147(1), pp.109-115 (1988).

5. S.C.Jain, Germanium-Silicon Strained Layers and Heterostructures, Acad. Press, Boston (1994)

6. R.People, J.Bean, Modulation Doping in $\mathrm{Ge}(\mathrm{x}) \operatorname{Si}(1-\mathrm{x})$ Strained Layer Heterostructures // Appl.Phys. Lett. 45(9), pp.1231-1235 (1984)

7. C.Walle, R.Martin, Theoretical calculations of heterojunction discontinuities in Ge/Si system // Phys. Rev. B. 34(8), pp.56215627 (1986).

8. K.A. Mader, A. Baldereschi, H. Von Kanel, Band structure and instability of $\mathrm{Ge}_{1-\mathrm{x}} \mathrm{Sn}_{\mathrm{x}}$ alloys // Solid State Communs. 69(12), pp.1123-1127 (1989).

9. R.Soref, and L.Friedman, Direct-gap Ge/GeSn/Si and GeSn/ $\mathrm{Ge} / \mathrm{Si}$ heterostructures // Superlattices Microstruct. 14(2/3), pp.189-195 (1993).

10. O.Gurdal, P.Desjardins, Low-temperature growth and critical epitaxial thickness of fully strained metastable $\mathrm{Ge}_{1-\mathrm{x}} \mathrm{Sn}_{\mathrm{x}}$ $(x<0.26)$ alloys on $\mathrm{Ge}(001) 2$ ?1 // J.Appl. Phys. 83(1), pp.162175 (1998).

11. R.A.Soref and C.H.Perry, Predicted band gap of the new semiconductor SiGeSn // J.Appl. Phys. 69(1), pp.539-545 (1991).

12. A.Khan and P.Berger, Band-edge photoluminescence from pseudomorphic $\mathrm{Si}_{0.96} \mathrm{Sn}_{0.04}$ alloy // Appl. Phys.Lett. 68(22), pp.3105-3110 (1996).

Fig. 10. Critical thickness for $\mathrm{Si}_{1-\mathrm{x}} \mathrm{C}_{\mathrm{X}} / \mathrm{Si}$ alloy. 


\section{G. Deibuk et al.: The effect of strain on the thermodynamic properties of...}

13. J.B.Posthil, R.A.Rudder, S.V.Hattagady, G.G.Fountain and R.J.Markunas, Direct-gap Ge/GeSn/Si and GeSn/Ge/Si heterostructures // Appl.Phys.Lett. 56, pp.734-780 (1990).

14. S.S.Iyer, K.Eberl, M.S.Gorsky // MRS Symposia proceedings No. 220 (Materials Research Society, Pittsburg, 1991), p.581567.

15. J.Tersoff, Modeling solid-state chemistry: Interatomic potentials for multicomponent systems // Phys. Rev. B, 39(8), pp.5566-5568 (1989).

16. V.G. Deibuk, Yu.G. Korolyuk, Molecular-dynamics simulation of structural properties of $\mathrm{Ge}_{1-\mathrm{x}} \mathrm{Sn}_{\mathrm{x}}$ substitutinal solid solutions // Semiconductors, 35(3), pp.298-300 (2001).

17. H.Gould and J.Tobochnik, in An Introduction to Computer Simulations Methods: Applications to Physical Sys tems (Addison-Wesley, Reading, 1988; Mir, Moscow, 1990), Part 1.

18. C.Lin, A.Li, The effect of strain on the miscibility gap in GaIn-Sb ternary alloy // J. of Crystal Growth, 203(2), 511-515 (1999).

19. R.Beanland, D.J.Dunstan, P.J.Goodhew, Plastic relaxation and relaxed buffer layers for semiconductor epitaxy // Adv.Phys. 45(2), pp.87-146 (1996).

20. U.Mezon, Dynamic of lattice, M. Mir, (1968).

21. Y.Bolhovitanov, O.Pchelyakov, Si-Ge epitaxial films and heterostructures // Uspehi Fizicheskih Nauk, 171(7), (2000).

22. R.Pandey, A theoretical study of stability, electronic, and optical properties of $\mathrm{GeC}$ and $\mathrm{SiC} / / J$. Appl. Phys., 88(11), pp.6462-6471 (2000). 